\title{
TIPOLOGIA DOS VEIOS DE QUARTZO E ESTUDO DE INCLUSÕES FLUIDAS NOS DEPÓSITOS DE OURO DA FAIXA MÓVEL AGUAPEI - CRÁTON AMAZÔNI- CO - MINA DE SÃO VICENTE, REGIÃO DA LAVRINHA E PAU-A-PIQUE
}

\author{
CARLOS JOSÉ FERNANDES ${ }^{1,4}$, RAUL MINAS KUYUMJIAN ${ }^{2,4}$, MÁRCIA ABRAHÃO \\ MOURA ${ }^{2}$, ELZIO DA SILVA BARBOZA ${ }^{1,4}$ \& GENOVA MARIA PULZ ${ }^{3,4}$
}

\begin{abstract}
Resumo A Faixa Móvel Aguapeí na porção sudoeste do Cráton Amazônico, forma um cinturão NW de aproximadamente 600 $\mathrm{km}$ por até $50 \mathrm{~km}$ de largura sustentado, principalmente, pelas rochas metassedimentares do Grupo Aguapeí. Este grupo ocorre sobre rochas básicas, ultrabásicas e sedimentares químicas do Terreno Rio Alegre (1,50 a 1,49 Ga) e sobre rochas graníticas do Terreno Santa Helena (1,48 a 1,42 Ga). Ao longo da faixa são registrados mais de 20 depósitos auríferos, em sua maioria associados ao Grupo Aguapeí (1,28 - 0,95 Ga) fortemente deformado pela Orogenia Sunsás-Aguapeí $(1,1-0,9 \mathrm{Ga})$. Foram estudadas três áreas ao longo da faixa: Norte (mina de São Vicente); Central (depósitos da região da Lavrinha); Sul (depósito Pau-a-Pique). O minério nestes depósitos é constituído por sistemas de veios de quartzo e disseminações nas encaixantes. Os teores mais elevados de ouro nos veios estão relacionados aos que apresentam texturas comb, sacaroidal e de substituição. $O$ ouro nativo ocorre associado a pirita, pirrotita, calcopirita, prata nativa, arsenopirita, galena hematita, magnetita e martita. Estudo de inclusões fluidas nos veios de quartzo desses depósitos revelam três populações de inclusões distribuídas em dois sistemas: trifásicas aquo-carbônicas $-\mathrm{H}_{2} \mathrm{O}+\mathrm{CO}_{2}+\mathrm{NaCl}$ (Tipo I) e; bifásicas aquosas e monofásicas aquosas $-\mathrm{H}_{2} \mathrm{O}+\mathrm{NaCl}$ (Tipos II e III), todos com baixa salinidade $(<8 \% \mathrm{em}$ peso $\mathrm{NaCl}$ eq.). Os fluidos estão relacionados a sistema hidrotermal profundo sendo a principal fonte para o ouro a devolatilização de pilhas de rochas ultramáficas, máficas e bifs das sequências vulcanosedimentares Rio Alegre e Pontes e Lacerda. Os dados petrográficos e geoquímicos, somados às idades ${ }^{40} \mathrm{Ar} /{ }^{39} \mathrm{Ar}$ em sericita obtida junto aos veios hidrotermais nos depósitos Pau-a-Pique e naqueles da região da Lavrinha com idades entre 908,1 $\pm 0,9$ Ma e 917,8 \pm 0,9 Ma para a mineralização, evidenciam a circulação de fiuidos no final da deformação do Grupo Aguapeí pela Orogenia Sunsas-Aguapeí dando um caráter epigenético à formação dos depósitos.
\end{abstract}

Palavras-chave: Tipologia de veios de quartzo, inclusões fluidas, Grupo Aguapeí, depósitos de ouro, conglomerados, Cráton Amazônico.

\begin{abstract}
QUARTZO VEIN TIPOLOGY AND FLUID INCLUSION STUDIES FOR GOLD DEPOSITS FROM THE AGUAPEI BELT-AMAZONIAN CRATON-SÃO VICENTE MINE, LAVRINHA REGION AND PAU-A-PIQUE DEPOSITS. The Aguapeí Belt in the SW region of the Amazonian Craton is a NW belt of approximately $600 \mathrm{~km}$ long and $50 \mathrm{~km}$ width. Its is mainly composed of metasedimentary rocks of the Aguapei Group. Basement of this group is represented by basic and ultrabasic rocks, and chemical metassediments of the Rio Alegre Terrain $(1,50 \mathrm{a} \mathrm{1,49} \mathrm{Ga})$ and granitic rocks of the Santa Helena Terrain $(1,48$ a 1,42 $\mathrm{Ga}$ ). More than 20 gold deposits were identified in this belt, most of them hosted in the Aguapei Group $(1.28-0.95 \mathrm{Ga})$, strongly deformed by the Sunsás-Aguapeí Orogeny (1.1-0.9Ga). Here we present studies for three areas along the belt: the northern portion (São Vicente Mine); the Central portion (Lavrinha region deposits); and the southern portion (Pau-a-Pique deposit). The gold in these three areas is in quartz veins systems and disseminated into the hosted rocks. Highest gold grades are observed in quartz veins with comb, saccharoidal and replacement textures. Native gold occurs associated with pyrite, pyrrotite, chalcopyrite, native silver, arsenopyrite, galena, hematite, magnetite and martite. Microthermometric studies in fluid inclusions of quartz veins display three inclusion populations distributed in two systems: trifhasic aquo-carbonic $-\mathrm{H}_{2} \mathrm{O}+\mathrm{CO}_{2}+\mathrm{NaCl}$ (type $\mathrm{I}$ ) and; biphasic aquous and monophasic aqueous $-\mathrm{H}_{2} \mathrm{O}+\mathrm{NaCl}$ (type II and III), both with low salinity $(<8 \mathrm{wt} \% \mathrm{NaCl}$ eq. $)$. Fluids are related with deep hydrothermal system, and the main gold source is attributed to the process affecting ultrabasic and basic rocks and BIFs from the Rio Alegre and Pontes e Lacerda sequences. Petrographic data and geochemistry studies, associeated with ${ }^{40} \mathrm{Ar} /{ }^{39} \mathrm{Ar}$ ages in sericites from hydrothermal veins of the Pau-a-Pique deposit and from the Lavrinha region, ranges from $908.1 \pm 0.9 \mathrm{Ma}$ to 917.8 $\pm 0.9 \mathrm{Ma}$ for the mineralization processes, indicating a strong fluid circulation at the ending of deformation processes that affected the Aguapei Group during the Sunsás-Aguapei Orogeny, that generated the epigenetic gold deposits.
\end{abstract}

Keywords: Quartz vein tipology, fluid inclusion, Aguapei Group, gold deposits, conglomerates, Amazonian Craton.

INTRODUÇ̃̃O A mina de São Vicente e os depósitos da região da Lavrinha e Pau-a-Pique, situados na Província Aurífera Alto Guaporé, estado de Mato Grosso (Saes et al. 1991), são considerados as mais importantes ocorrências de ouro registradas nas rochas metassedimentares do Grupo Aguapeí (Fig. 1). A produção oficial de ouro nesta província no período de 1990 a 1995 chegou a 6 toneladas (Brasil, 1996), número que não reflete a quantidade real de ouro extraída pelos garimpeiros nas mais de 20 ocorrências ao longo de toda a Faixa Móvel Aguapeí.

A região insere-se no contexto geológico do Cráton Amazô- nico (Almeida et al. 1976), na sua porção meridional, designada por Almeida et al. (1977) de Província Tapajós, e, mais precisamente na Subprovíncia Madeira.

Espessas seqüências sedimentares de origem transgressivaregressiva e coberturas recentes recobrem grande parte do Cráton Amazônico. Dentre as seqüências, apenas o Grupo Aguapeí (Souza \& Hildred, 1980), de idade Mesoproterozóica, anteriormente denominado Unidade Aguapeí (Figueiredo et al. 1974), está representado na área. O ouro ocorre associado a sistemas de veios de quartzo e disseminado nas rochas desse grupo, par-

1 - Instituto de Ciências Exatas e da Terra, UFMT, MT, Cuiabá, Av. Fernando Correa, Bairro Coxipó CEP. 78060-900

2 - Instituto de Geociências, UnB, DF, Brasília, Campus Universitário Darcy Ribeiro, CEP.70919-970 cafer@cpd.ufmt.br

3 - Instituto de Geociências, UFRGS, RS, Porto Alegre, Av. Bento Gonçalves 9500, Bairro Agronomia, CEP 91509-900

4 - Grupo de Pesquisa Recursos Minerais de Mato Grosso - $\mathrm{CNPq}$ 
- Ocorrências de Ouro
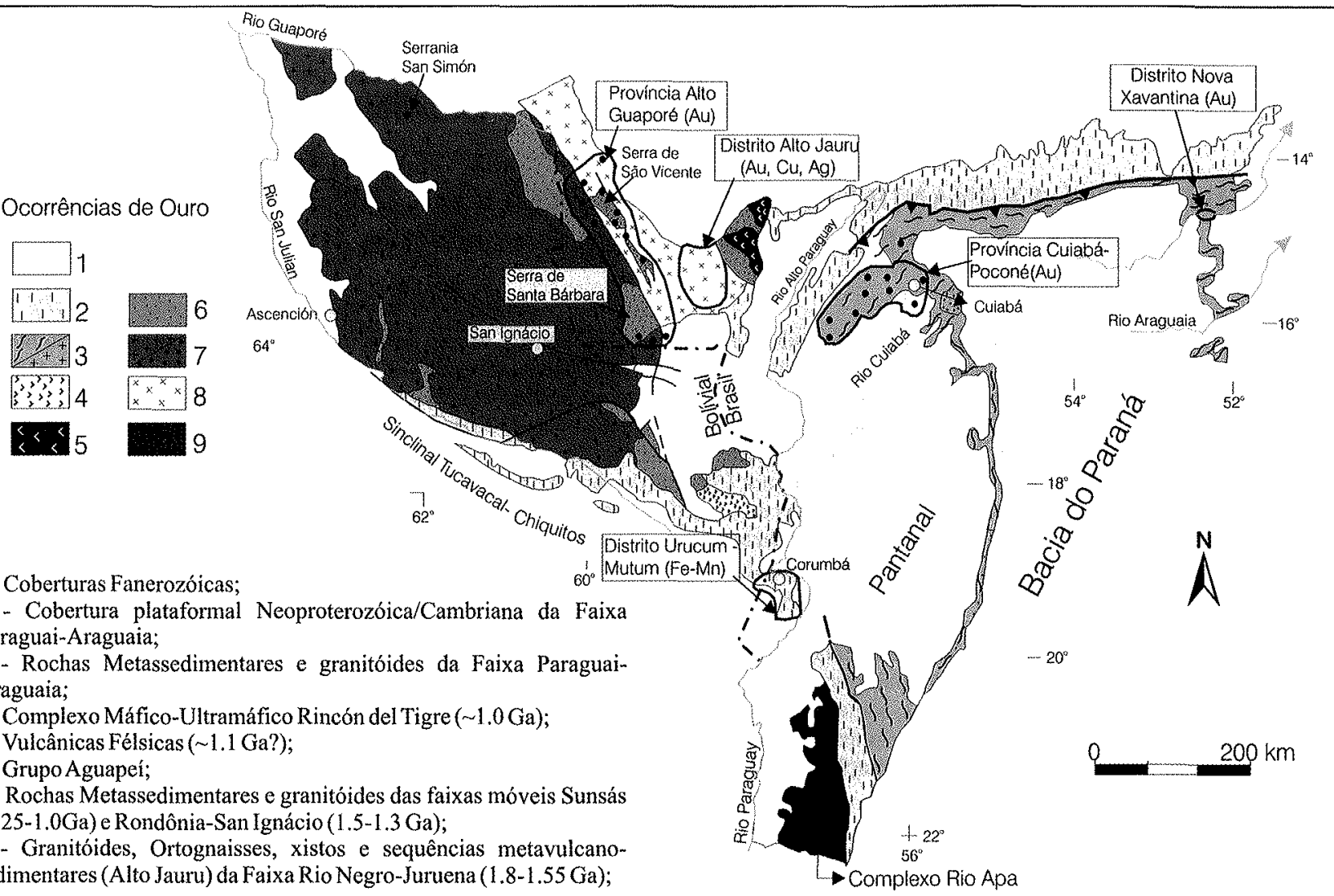

1 - Coberturas Fanerozóicas;

2 - Cobertura plataformal Neoproterozóica/Cambriana da Faixa Paraguai-Araguaia;

3 - Rochas Metassedimentares e granitóides da Faixa ParaguaiAraguaia;

4- Complexo Máfico-Ultramáfico Rincón del Tigre $(\sim 1.0 \mathrm{Ga})$

5 - Vulcânicas Félsicas ( 1.1 Ga?);

6- Grupo Aguapeí;

7 - Rochas Metassedimentares e granitóides das faixas móveis Sunsá (1.25-1.0Ga) e Rondônia-San Ignácio (1.5-1.3 Ga);

8 - Granitóides, Ortognaisses, xistos e sequências metavulcanosedimentares (Alto Jauru) da Faixa Rio Negro-Juruena (1.8-1.55 Ga);

Figura 1 - Mapa geológico esquemático do sudoeste do Cráton Amazônico e das faixas Paraguai e Araguaia, com a localização das províncias metalogenéticas (modificado de Trompette, 1994; Litherland et al. 1985; Tassinari \& Macambira, 1999 - in: Dardene \& Schobbenhaus, 2001).

ticularmente nas porções deformadas que caracterizam a Faixa Móvel Aguapeí.

Este trabalho retrata o estudo de inclusões fluidas nos veios de quartzo auríferos, sua tipologia, com o objetivo de estimar as condições físico-químicas dos fluidos responsáveis pela mineralização ao longo dos $200 \mathrm{~km}$ da Faixa Móvel Aguapeí que ocorrem na porção sudoeste do estado de Mato Grosso, Brasil. Foram estudados, como representantes dessas mineralizações, a mina de São Vicente (norte da faixa), os depósitos da região da Lavrinha (central) e o depósito Pau-a-Pique (sul).

GEOLOGIA REGIONAL O Craton Amazônico foi compartimentado em 6 províncias geocronológicas por Tassinari \& Macambira, (1999) com base baseados em datações geocronológicas, alinhamentos estruturais, tipos de rocha e evidências geofísicas. Na porção sudoeste do estado de Mato Grosso e leste boliviano ocorrem somente as províncias Rio Negro-Juruena (1,8 - 1,55 Ga); Rondoniana-San Ignácio (1,5 - 1,3 Ga) e Sunsás $(1,25-1,0 \mathrm{Ga})$, sendo a região de estudo é representada em sua maioria pela última província (Fig. 1).

A Província Sunsás é a unidade mais jovem do Cráton Amazônico, sendo o início de evolução tectônica, crono-correlato com o Ciclo Orogênico Grenville (1,3 - 1,0 Ga) na Laurentia e Báltica e marcado por uma importante fase distensional continental. Magmatismo basáltico e a deposição em um ambiente de margem continental dos sedimentos dos grupos Sunsás e Vibosi na Bolívia e do Grupo Aguapeí no Brasil, representam esta fase distensiva. Litherland \& Bloomfield (1981), Litherland \& Power (1989) e Alvarenga \& Saes (1992) correlacionam o Grupo Aguapeí com o Grupo Sunsás na Bolívia, indicando provável elo entre as bacias. Estas bacias passaram por processo de inversão e foram fechadas durante o desenvolvimento das faixas móveis Sunsás e Aguapeí respectivamente (Tassinari et al. 2000, Fernandes et al. 2003a).

Segundo Saes (1999) o Grupo Aguapeí, formado entre 1,28 e $0,95 \mathrm{Ga}$, compreende rochas sedimentares depositadas em aulacógeno desenvolvido junto à sutura do Terreno Rio Alegre e Santa Helena, os quais representam parte da Província Geocronológica Rondoniana-San Ignácio de Tassinari e Macambira (1999). O Terreno Santa Helena ocorre em sua maioria a leste das áreas e é representado por batólito alongado na direção NW, que consiste de granitos e granodioritos com idades $\mathrm{U} / \mathrm{Pb}$ variando de 1,45 a 1,42 Ga (Fig. 2) (Geraldes et al. 2001). Já o Terreno Rio Alegre, caracterizado como ofiolito por Saes (1999), ocorre em sua maioria a oeste e inclui rochas juvenis vulcânicas e plutônicas máficas de idade 1,52 a 1,47 Ga (Fig. 2) (Geraldes et al. 2001).

Segundo Souza \& Hildred (1980), Saes \& Leite (1993) e Saes (1999), o Grupo Aguapeí é composto por três formações, denominadas, da base para o topo: Fortuna, constituída de conglomerados oligomíticos e arenitos quartzosos com raras intercalações de siltitos depositados em estágio rift; Vale da Promissão, composta por siltitos, argilitos e arenitos subordinados formados em estágio sinéclise; e Morro Cristalina, composta de arenitos com intercalações de conglomerados e finos leitos de siltitos, depositados em ambientes fluviais entrelaçados e dunas eólicas durante estágio de inversão. $\mathrm{O}$ embasamento e os sedimentos da porção central desta bacia foram deformados e metamorfizados na fácies xisto verde pela Orogenia Sunsás-Aguapeí (1,1 - 0,9 Ga) gerando a Faixa Móvel Aguapeí, ao longo da qual situam-se as ocorrências auríferas (Fig. 1 e 2). 


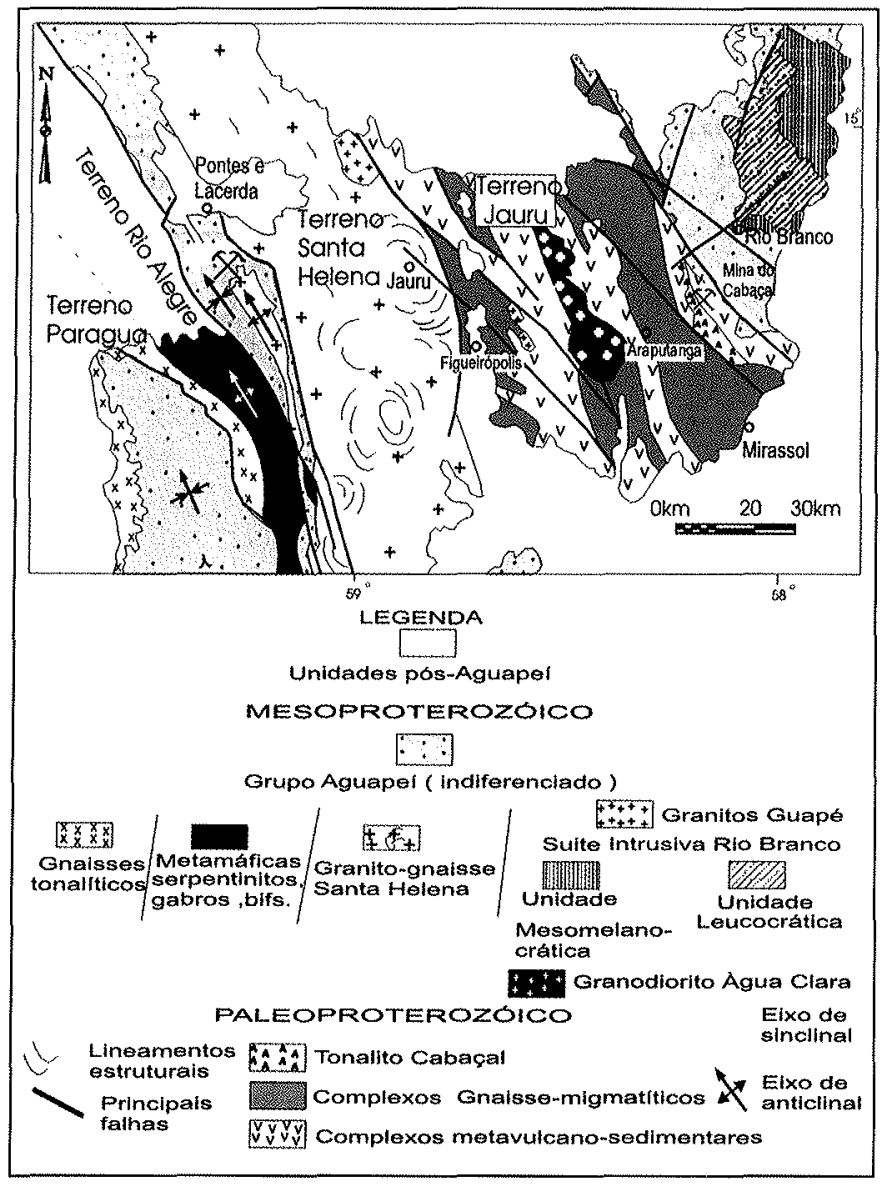

Figura 2 - Esboço geológico do sudoeste do estado de Mato Grosso (Modificado de Saes et al. 1984, Saes 1999 e Monteiro et al. 1986).

\section{GEOLOGIA DOS DEPÓSITOS, E TIPOLOGIA DOS} VEIOS DE QUARTZO Em todos os depósitos auríferos registrados no Grupo Aguapeí (Fig. 3) o ouro ocorre associado a sistemas de veios de quartzo e disseminações nas encaixantes, tendo como paragênese do minério sulfetos e óxidos, representados em ordem decrescente de abundância por pirita, magnetita, hematita, ilmenita e martita, e, subordinandamente, calcopirita, pirrotita, arsenopirita e galena (Fernandes et al. 1999; Barboza et al. 2001).

Nos depósitos auríferos do Grupo Aguapeí a alteração hidrotermal das rochas metassedimentares concentram-se onde essas estão milonitizadas. A ocorrência do minério predominantemente nas zonas de alta deformação, somada à ausência de orientação da maioria dos minerais hidrotermais e por vezes abundância de estilolitos no minério, indicam que a percolação de fluidos ocorreu nos estágios finais da deformação.

$\mathrm{Na}$ Formação Fortuna as rochas mineralizadas associam-se a rochas que foram submetidas a silicificação, sericitização, sulfetação, oxidação e turmalinização. Nas proximidades dos corpos tonalíticos que compõem parte do embasamento dos depósitos do Pau-a-Pique e aqueles do Horizonte Inferior na região da Lavrinha ocorrem biotitização, cloritização, epidotização.

Mina de São Vicente Esta mina, descrita por Passos Jr. et al. (1997), Silva \& Chemale Jr, (1997), Scabora \& Duarte (1998) e Fernandes et al. (2003a), situa-se em rochas metassedimentares da Formação Fortuna, dispostas ao longo de uma faixa de maior deformação com cerca de $1 \mathrm{~km}$ de largura e direção $\mathrm{N} 40^{\circ} \mathrm{W}$, margeada, a leste e oeste, por estratos fracamente dobrados da mesma formação. Em alguns locais, devido a falhamentos reversos de SW para NE, as rochas do embasamento são colocadas entre as rochas do Grupo Aguapeí, delimitando faixa de elevada deformação, onde concentram os depósitos auríferos.

O ouro ocorre principalmente nos veios de quartzo sub-horizontais de espessura milimétricas a centimétricas (ouro grosso e baixo teor) e em suas encaixantes (fino), apresentando uma associação mineralógica composta por $\mathrm{Au}+$ pirita+arsenopirita +quartzo.

São evidenciadas duas fases de mineralização: (i) uma primeira fase sindeformacional, com ouro fino associado a zonas cloríticas paralelas ao acamamento, cujos teores estão em torno de 0,6 g/t Au (Fig. 4); (ii) uma segunda fase, extensional, com ouro mais grosso associado à sílica e aos sulfetos, com teores médios na ordem de $1,0 \mathrm{~g} / \mathrm{t}$ Au ( Scabora \& Duarte, 1998, Silva et al. 1997, Dardenne \& Schobbenhaus, 2001) (Fig. 4).

Ocorrem dois conjuntos de veios de quartzo: o primeiro representado por veios de até $30 \mathrm{~cm}$ de largura, geralmente boudinados, ocorre paralelo à foliação milonítica sub-vertical, ora mergulhando para SW ora para NE, marcada principalmente pela orientação da mica branca. Às vezes formam estruturas do tipo saddle reef que podem atingir 1 metro de espessura (Fig. 4). O segundo conjunto é representado por veios sub-horizontais que chegam a formar bolsões de quartzo de até $3 \mathrm{~m}$, que seccionam a foliação milonítica formando zona mineralizada tabular.

Depósitos da região da Lavrinha Os depósitos da região da Lavrinha têm sido alvo de vários estudos que enfocam a gênese e o controle das mineralizações primárias (Geraldes et al. 1997; Pinho et al.1999, Santos et al. 2001, Fernandes et al. 2003b). As diversas ocorrências situam-se em diferentes níveis da Formação Fortuna - nos metaconglomerados oligomíticos da base, nos metargilitos e metassiltitos da porção intermediária e nos metarenitos e metaconglomerados da porção superior. Invariavelmente os veios mineralizados exibem uma história deformacional relacionada aos movimentos contracionais, de baixo ângulo, que propicia o cavalgamento do Grupo Aguapeí sobre o embasamento representado pelos terrenos Santa Helena e Rio Alegre.

Segundo Fernandes et al. (2003b), na região da Lavrinha o ouro ocorre associado a abundantes veios encaixados em três horizontes denominados de Inferior, Intermediário e Superior. Nos horizontes Inferior (Zona de Cisalhamento Morro Solteiro) e Intermediário ocorrem veios de cisalhamento, de brecha $\mathrm{e}$, menos comumente, veios extensionais e oblíquos segundo a classificação de Hodgson (1989).

Os veios de cisalhamento, de aspecto maciço, mas bastante fraturados, ocorrem paralelos à foliação milonítica penetrativa $\mathrm{S} 1\left(\mathrm{~N} 30^{\circ} \mathrm{W} / 45^{\circ} \mathrm{NE}\right.$ no Depósito do Ernesto Inferior; $\mathrm{N} 20^{\circ} \mathrm{W} /$ $45^{\circ} \mathrm{SW}$ nos depósitos do Clementino e Copacel 1) e apresentam espessuras geralmente variando de 3 a $20 \mathrm{~cm}$, porém em algumas porções podem chegar a formar bolsões de 1 por $2 \mathrm{~m}$ de espessura, como no depósito do Ernesto Inferior. Apresentam formas em sigmóides, tabulares e em $\mathrm{S}$ sendo que, às vezes, podem estar boudinados e/ou dobrados juntos com a foliação. Os veios brechados apresentam formas variadas como os do tipo centopéia (Hodgson, 1989) que ocorrem no Depósito do Ernesto Inferior (Fernandes et al. 2005).

No Horizonte Superior, veios de cisalhamento, paralelos à foliação milonítica $S 1$ e com até $30 \mathrm{~cm}$ de espessura são mais comuns nas zonas mineralizadas (Depósito do Jair/Lavrinha, Japonês e Nosde) (Fig. 5). Ocorrem tanto confinados ao pacote de metapelitos como nos milonitos gerados por deslizamentos flexurais nos níveis de metaconglomerados e metarenitos que compõem o topo da seqüência estratigráfica. É comum observar no fechamento das dobras geradas, principalmente na in- 


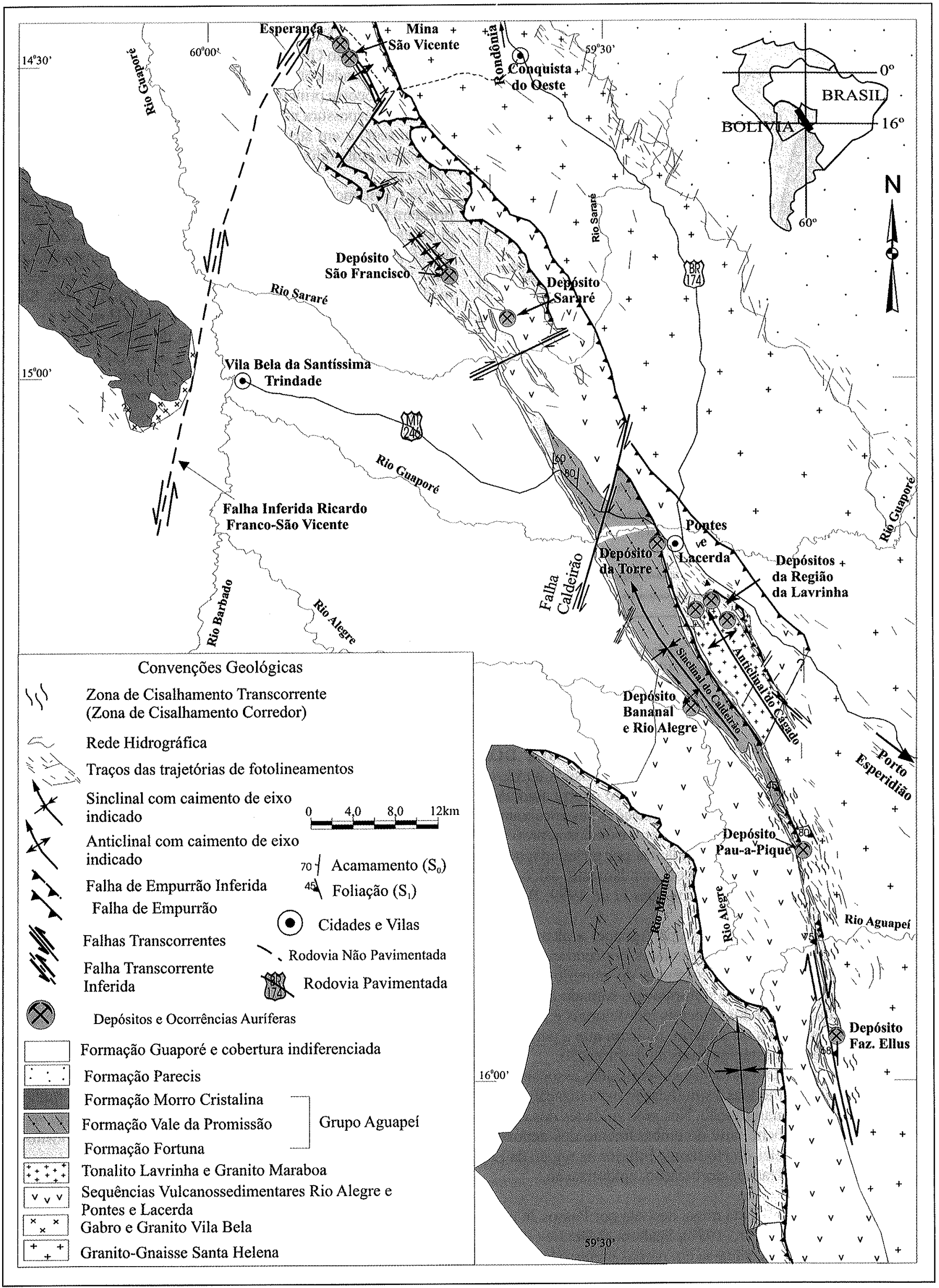

Figura 3 - Mapa geológico da porção sudoeste do Estado de Mato Grosso - fronteira Brasil/Bolívia (Fernandes et al. 2003b). 


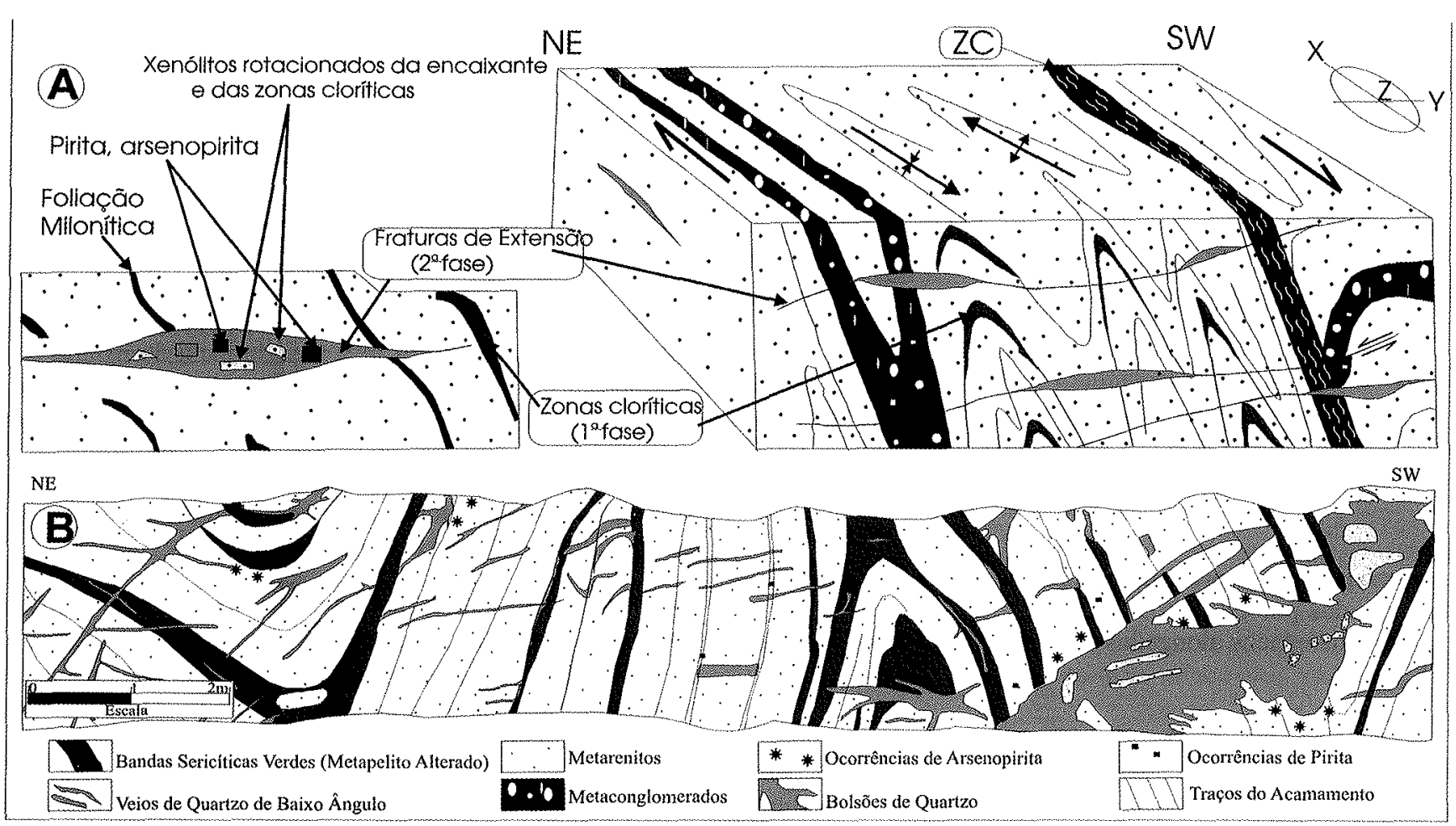

Figura 4 - (A) Tipologia da mineralização aurifera na mina de São Vicente; (B) Perfil geológico detalhado de trecho da parede da galeria de pesquisa $S V$-GI mostrando bandas sericiticas onde se concentra o ouro fino, cortadas por veios e bolsões de quartzo com ouro grosso (Modificado de Scabora, 1992; Scabora \& Duarte, 1998 e Saes 1999).

terface metapelitos-metarenitos, a ocorrência de veios em sela (Saddle Reef).

Os veios extensionais e oblíquos, variando de 5 a $15 \mathrm{~cm}$ de espessura, são sintaxiais e geralmente estéreis. São tabulares, de aspecto maciço e se encaixam paralelos à foliação S2 (clivagens disjuntiva e de crenulação). No depósito do Nosde estes veios são comuns, estando paralelos ao plano axial das dobras e/ou oblíquos, geralmente com direção NE (Fig. 5).

Depósito Pau-a-Pique Este depósito, situado na serra homônima, foi descrito por Fernandes (1999) que vinculou a gênese dos veios de quartzo auríferos deste depósito a abundantes fraturas desenvolvidas em todos os litótipos, mas com maior freqüência nos milonitos gerados a partir dos metaconglomerados da Formação Fortuna e do Tonalito Pau-a-Pique. Segundo este autor o minério condiciona-se às estruturas subsidiárias da Zona de Cisalhamento Corredor, especialmente na intersecção de fraturas D e $\mathrm{R} \mathrm{e}$, menos comumente, às fraturas T, R', $\mathrm{P}$ e P' (Fig. 6).

Os veios de quartzo são descontínuos, com formas de tabletes de chocolate (Ransay, 1967), constituídos por boudins assimétricos de dimensões centimétricas a métricas. Internamente esses veios exibem tanto estilolitos como fragmentos de minerais, precipitados juntamente com os veios (sulfetos, óxidos, micas e turmalina) do halo hidrotermal adjacente (Fernandes et al. 1999). Os estilolitos que seccionam o quartzo são abundantes em alguns veios, sugerindo que a atuação de mecanismos de solução por pressão pode ter contribuído para a remobilização interna do ouro (Gilligan \& Marshall, 1989).

Fernandes et al. (1999) fizeram classificação textural dos veios de quartzo encaixados nos diversos tipos de fraturas no depósito Pau-a-Pique, conforme metodologia de Dowling \& Morrison (1989), a qual leva em conta a forma, tamanho e orientação preferencial dos grãos de quartzo bem como pela natureza e intensidade da deformação e recristalização do quartzo.

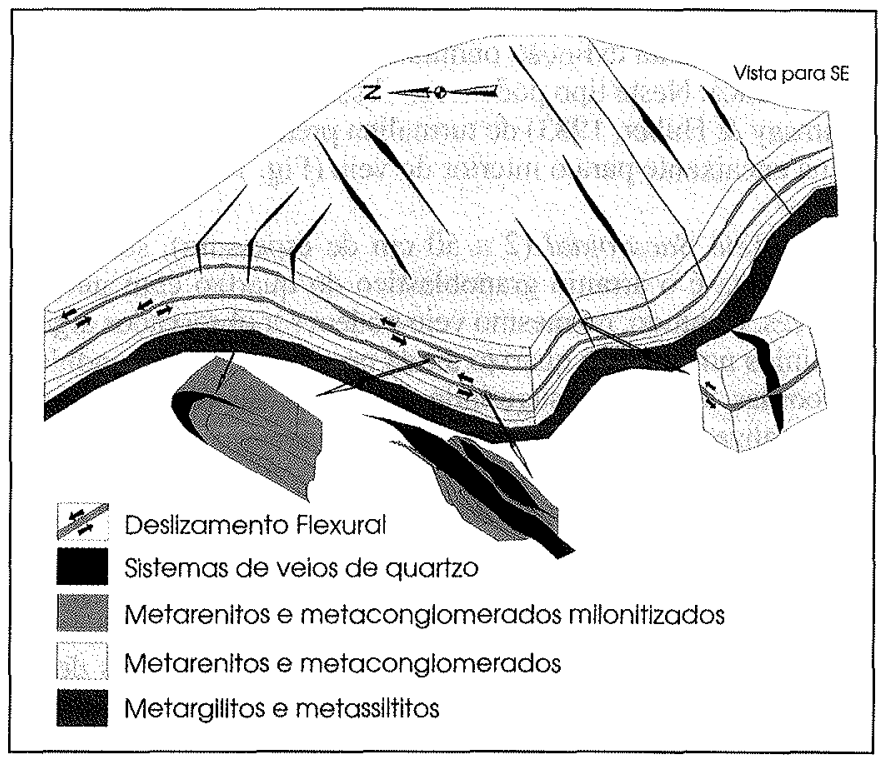

Figura 5 - Modelo esquemático do sistema de mineralização para o depósito do Nosde, Horizonte Superior.

As seguintes variedades texturais de veios foram reconhecidas:

1 - Veio Maciço (até $2 \mathrm{~m}$ de espessura). O quartzo apresentase com fraturas realçadas por uma superfície avermelhada de alteração dos minerais opacos. Intersticiais ao quartzo aparecem mica branca, epidoto e minerais opacos (Fig. 7A).

2 - Veios com testura pente (comb) (até $1 \mathrm{~m}$ de espessura). Os cristais de quartzo estão recobertos por hematita. Nestes veios também ocorrem mica branca e turmalina. Em lâmina delgada, 


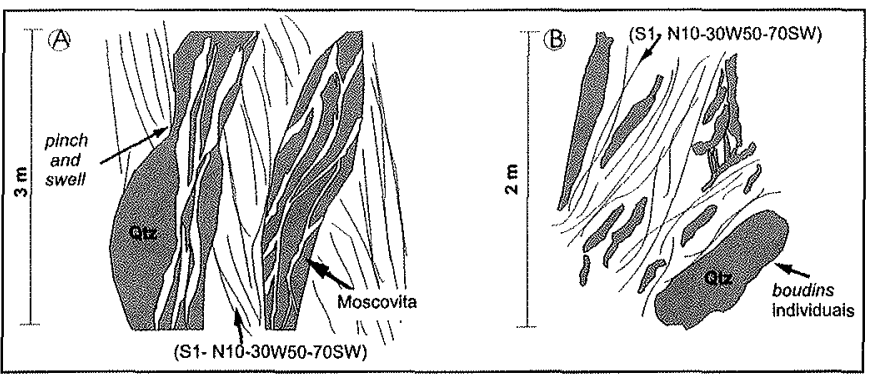

Figura 6 - Croquis esquemáticos dos veios de quartzo no depósito Pau-a-Pique. (A) Estruturas "pinch and swell" nos veios de quartzo; (B) Boudins individuais, destacando a variação de geometria e dimensões destas estruturas.

o quartzo $(<4 \mathrm{~mm})$ apresenta extinção ondulante. Seus contatos são realçados por estilolitos delineados por mica branca e/ ou por minerais opacos alongados segundo o eixo de deformação X (Fig. 7B).

3 - Veio de Substituição (10 a $30 \mathrm{~cm}$ de espessura). O quartzo mostra-se maciço com boxworks resultantes do intemperismo da pirita. Nestes veios também ocorrem mica branca, turmalina e minerais opacos. O quartzo contém inclusões de sulfetos e óxidos e mostra extinção ondulante e contatos suturados, sugerindo processos de recuperação/substituição (Vernon, 1986) (Fig. 7C).

4 - Veio Ribbon (10 a $40 \mathrm{~cm}$ de espessura). O quartzo aparece estirado devido a deformação da Zona de Cisalhamento Corredor. Lamelas de mica branca e turmalina ocorrem em interstícios da matriz quartzosa. $O$ quartzo varia de incolor a leitoso, apresenta extinção ondulante e, por vezes, inclusões de mica branca. Neste tipo podem ser observados cristais sintaxiais (Ramsay \& Huber, 1983) de turmalina preta que se projetam da rocha encaixante para o interior do veio (Fig. 7D).

5 - Veio Sacaroidal (2 a $50 \mathrm{~cm}$ de espessura), sua feição diagnóstica é o arranjo granoblástico do quartzo com junções tríplices. Contudo, no mesmo veio podem ser observados alguns domínios nos quais o quartzo ainda preserva extinção ondulante, bordas suturadas, sugerindo processos de rescristalização não finalizados (Fig. 7E).

Nos veios Comb (Fig. 7B3) e de Substituição (Fig. 7C3), os teores de ouro variam de 0,2 a $1,2 \mathrm{ppm}$, enquanto naqueles com textura Sacaroidal variam de 0,12 a $0,26 \mathrm{ppm}$ (Fig. 7E3). Nos demais tipos de veios, os teores de Au situaram-se abaixo do limite de deteç̧ão. Nenhuma correlação entre os teores de $A u$ com os dos outros elementos foi identificada via regressão linear, sugerindo que apenas os próprios teores de $\mathrm{Au}$ possibilitam a diferenciação dos veios férteis daqueles estéreis.

\section{ESTUDO DE INCLUSÕES FLUIDAS}

Material e Métodos Um total de 30 amostras de veios de quartzo foi coletado, sendo 5 na mina de São Vicente, 12 na região da Lavrinha (depósitos Copacel 1, Clementino, Milton Brasileiro, Copacel 2, Ernesto Inferior) e 13 no depósito Paua-Pique. A preparação das amostras e as medidas microtermométricas foram executadas seguindo os procedimentos descritos por Roedder (1984) e Shepherd et al. (1985).

Para o estudo de microtermometria das amostras da mina de São Vicente e dos depósitos da Lavrinha foi utilizada Platina de resfriamento/aquecimento LINKAM THMSG $600^{\oplus}$ acoplada ao microscópio petrográfico OLYMPUS $B X 50^{\oplus}$ no laboratório de inclusões fluidas da Universidade de Brasília (IG/UnB).

A calibração do equipamento foi feita utilizando inclusões sintéticas. As amostras foram resfriadas usando $\mathrm{N}_{2}$ líquido até cerca de $-190^{\circ} \mathrm{C}$. O aquecimento foi obtido mediante a utilização do aparelho LINKAM TMS $93^{\text {(1) }}$ com capacidade de aquecimento até $600^{\circ} \mathrm{C}$.

Para o depósito Pau-a-Pique, o estudo de microtermometria foi realizado em platina Chaixmeca ${ }^{\hat{\Lambda}}$ acoplada ao microscópio petrográfico Zeiss ${ }^{\hat{A}}$ no Laboratório de Inclusões Fluidas da Universidade Federal do Rio Grande do Sul (CPGq/IG/UFRGS). A calibração do aparelho foi feita usando inclusão natural aquocarbônica trifásica. As amostras foram resfriadas a cerca de $-190^{\circ} \mathrm{C}$ com nitrogênio líquido $\left(\mathrm{N}_{2}\right)$ e aquecidas a $400^{\circ} \mathrm{C}$ com o sistema digital Euroterm ${ }^{\hat{A}} 98$ (Barboza et al. 2001).

A salinidade, a composição global e a densidade das inclusões aquo-carbônicas foram estimadas com o auxílio do programa MacFlincor (Brown \& Hagemann 1994).

\section{PETROGRAFIA DAS INCLUSÕES FLUIDAS E MICRO-} TERMOMETRIA O estudo petrográfico possibilitou a distinção entre inclusões primárias e secundárias e o reconhecimento de três conjuntos de inclusões fluidas nos depósitos estudados, denominadas:

Tipo I. São inclusões trifásicas aquo-carbônicas em temperatura ambiente (Figs. $8 \mathrm{~B} \mathrm{e} \mathrm{E}$ ). Apresentam formas que variam de cristais negativos a irregulares e mostram dimensões entre 3 a $25 \mu \mathrm{m}$. Sua fase carbônica (L2+V) ocupa de 10 a $55 \%$ do volume total da inclusão, sendo que na mina de São Vicente pode chegar a $85 \%$.

Tipo II. São inclusões bifásicas aquosas (liquído + vapor). Apresentam dimensões variando de 4 a $35 \mu \mathrm{m}$ e formam cristais negativos, alongados ou irregulares (Fig. $8 \mathrm{C} \mathrm{e} \mathrm{F}$ ). O grau de preenchimento da fase vapor varia de 10 a $90 \%$, com o predomínio daquelas com 10 a $30 \%$.

Tipo III. São inclusões monofásicas aquosas constituídas ou por fase líquida ou vapor. Ocorrem geralmente em trilhas que por vezes seccionam toda a amostra (Figs. 8D e G). As inclusões monofásicas nas amostras dos depósitos da região da Lavrinha e da mina São Vicente apresentaram fusão do gelo geralmente em temperaturas positivas, caracterizando metaestabilidade. No depósito Pau-am-Pique, além da metaestabilidade, estas inclusões apresentam diâmetro inferior a $1 \mu \mathrm{m}$ e, por vezes, estão vazadas, dificultando a observação das mudanças de fase durante os testes microtermométricos. Assim, esta família de inclusões não será considerada na discussão a seguir.

As inclusões secundárias ocorrem em trilhas (microfraturas) que geralmente cortam toda a amostra (Fig. $8 \mathrm{H}$ ), podendo ser do Tipo III (Monofásicas) e do Tipo II (Bifásicas). Todos os três tipos de inclusões fluidas descritos podem ocorrer em uma mesma amostra.

Fator comum nas amostras é a presença de feições de crepitação, geralmente relacionadas às inclusões distribuídas em trilhas. Estas crepitações se deram provavelmente pela deformação progressiva imposta aos veios de quartzo (Fig. 8A).

Dois sistemas teóricos são sugeridos, a partir dos dados de microtermometria para representarem os fluidos das inclusões investigadas: $\mathrm{H}_{2} \mathrm{O}+\mathrm{CO}_{2}+\mathrm{NaCl}$ (Tipo I) e $\mathrm{H}_{2} \mathrm{O}+\mathrm{NaCl}$ (Tipo Il e Tipo III). A síntese dos dados microtermométricos é apresentada na tabela 1.

Nas amostras de veios de quartzo da mina São Vicente, porção norte da Faixa Móvel Aguapeí (Tab. 1 e Fig. 9A), as inclusões aquo-carbônicas (Tipo I) apresentam temperatura de 

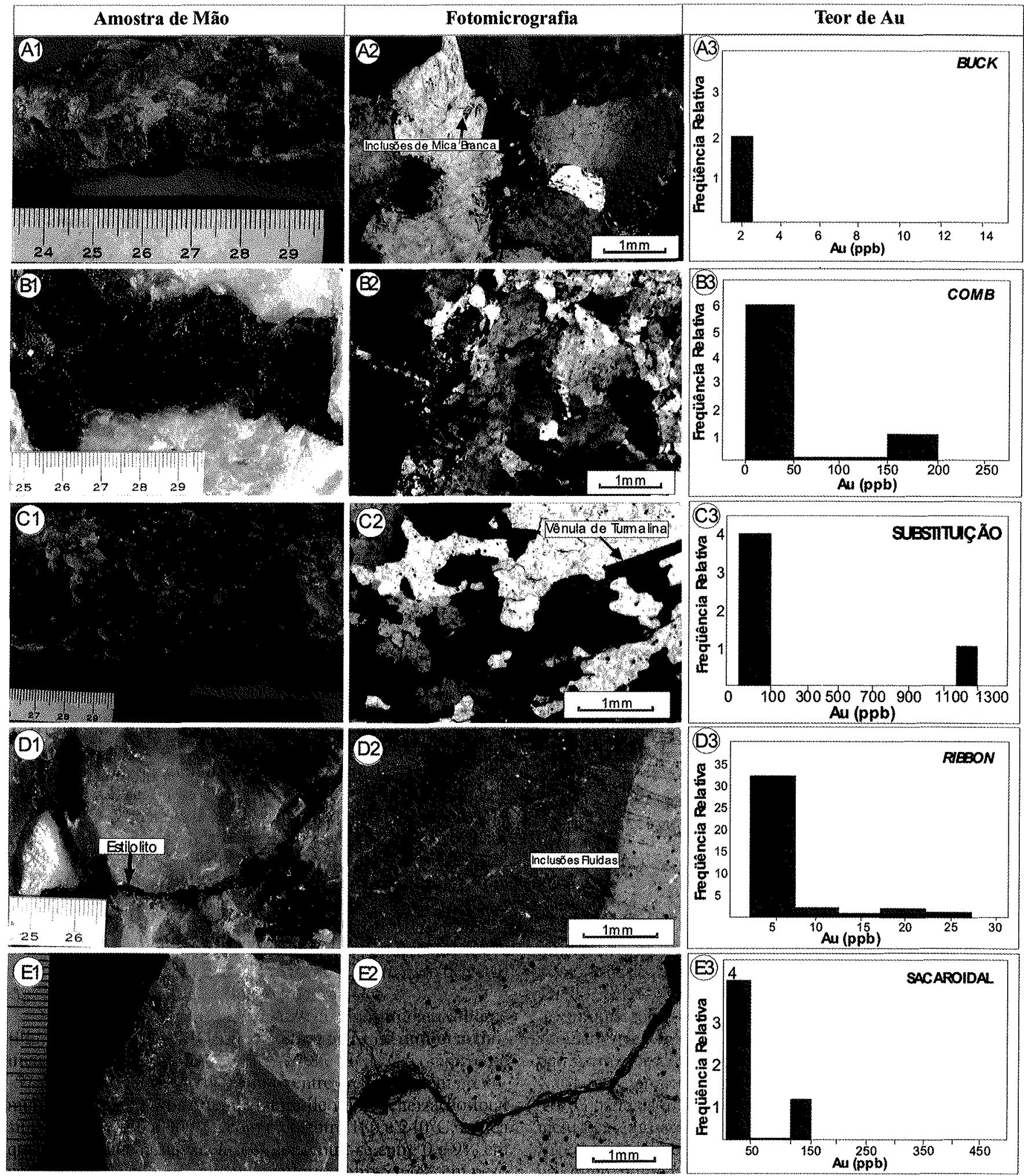

Figura 7 - Tipos texturais de veios de quartzo no depósito do Pau-a-Pique.(A) veio com textura maciça; (B) - veio com textura em pente com cristais de quartzo cobertos por hematita. (C) - veio com textura de substituição ilustrando seu contato antitaxial com os filossilicatos da encaixante. (D) veio com textura fitada com quartzo alongado e seccionado por estilolitos realçados por mica branca. (E) veio com textura sacaroidal fraturado (Fernandes, 1999; Fernandes et al. 1999).

fusão do $\mathrm{CO}_{2}$ entre -58 e $-56,6^{\circ} \mathrm{C}$, predominando valores entre $-56,9$ e $-56,6^{\circ} \mathrm{C}$. Estes valores indicam que a fase carbônica é constituída predominantemente por $\mathrm{CO}_{2}$, possivelmente acompanhada por concentrações muito subordinadas de outros voláteis (e.g. $\mathrm{CH}_{4}$ ou N $\mathrm{N}_{2}$ ), apesar de ocorrerem valores com fusão em $-56,6^{\circ} \mathrm{C}$, o que demostra a existência de fluidos aquo-carbônicos nos mesmos veios de quartzo. A fusão do clatrato situa-se entre 6,6 e $10,2^{\circ} \mathrm{C}$, com predomínio entre 8,4 e $9,6^{\circ} \mathrm{C}$, enquanto a temperatura de homogeneização total varia de 260 a $410^{\circ} \mathrm{C}$, com pico entre 340 e $360^{\circ} \mathrm{C}$. A salinidade dessas inclusões aquo-carbônicas, calculada com base na temperatura de fusão do clatrato, corresponde a valores entre 0,5 e $6,5 \%$ em peso de 


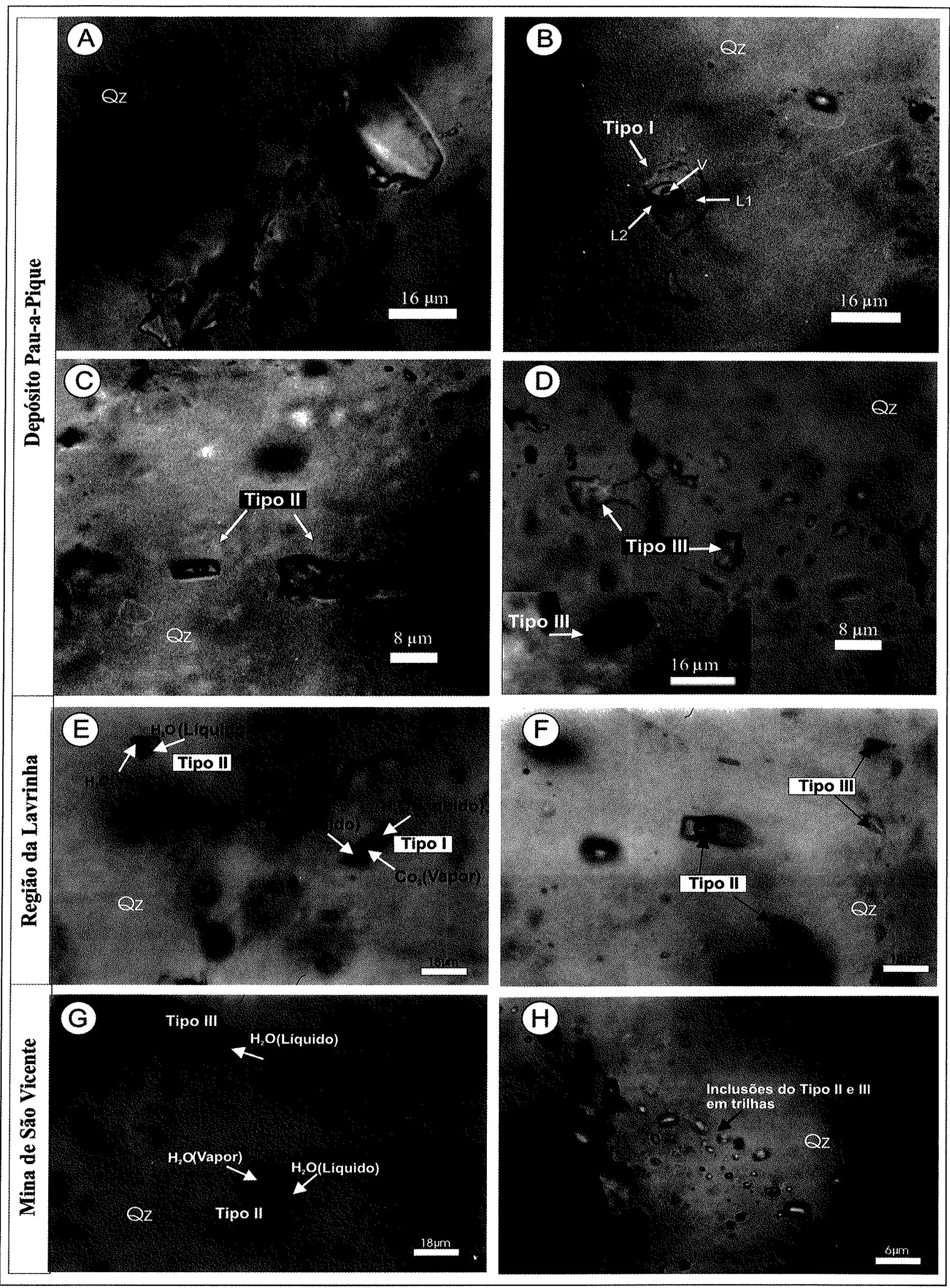

Figura 8 - Fotomicrografias das inclusões nos depósitos auriferos ao longo da Faixa Móvel Aguapei A a D depósito do Pau-aPique; E e F depósitos da região da Lavrinha e; $G$ e H mina de São Vicente. 
Tabela 1 - Resumo dos dados microtermométricos das inclusões fluidas nos veios de quartzo dos depósitos auríferos ao longo da Faixa Móvel Aguapeí.

\begin{tabular}{|c|c|c|c|c|c|c|c|c|c|}
\hline $\begin{array}{c}\text { Faixa } \\
\text { Móvel } \\
\text { Aguapeí }\end{array}$ & Depósitos & Inclusões Fluidas & $\begin{array}{c}\text { Tipos e } \\
\text { Composições }\end{array}$ & $\begin{array}{l}\mathrm{TfCO}_{2} \\
\left({ }^{\circ} \mathrm{C}\right)\end{array}$ & $\begin{array}{c}\mathrm{ThCO}_{2} \\
\left({ }^{\circ} \mathrm{C}\right)\end{array}$ & TfClat & TfGelo & $\begin{array}{c}\text { Salinidade } \\
\% \text { peso eq. } \\
\mathrm{NaCl} \\
\end{array}$ & $\mathrm{THt}\left({ }^{\circ} \mathrm{C}\right)$ \\
\hline \multirow{2}{*}{$\begin{array}{l}\text { Porção } \\
\text { Norte }\end{array}$} & \multirow[t]{2}{*}{ São Vicente } & $\begin{array}{l}\text { Trifásicas aquo- } \\
\text { carbônicas }\end{array}$ & $\begin{array}{c}\mathrm{I} \\
\mathrm{H}_{2} \mathrm{O}+\mathrm{CO}_{2}+\mathrm{NaCl}\end{array}$ & $\begin{array}{l}-58,1 \mathrm{a} \\
-56,6 \\
\end{array}$ & $\begin{array}{c}22,3 \mathrm{a} \\
29,5 \\
\end{array}$ & $\begin{array}{l}6,6 \mathrm{a} \\
10,2 \\
\end{array}$ & $\ldots$ & 0,4 a 5,8 & $\begin{array}{c}260 a \\
410 \\
\end{array}$ \\
\hline & & Bifásicas Aquosas & $\begin{array}{c}\mathrm{II} \\
\mathrm{H}_{2} \mathrm{O}-\mathrm{NaCl}\end{array}$ & $\cdots$ & $\cdots$ & $\ldots$ & $\begin{array}{c}-5,8 \mathrm{a}- \\
0,4\end{array}$ & 0,7 a 5,3 & $\begin{array}{c}150 \mathrm{a} \\
270\end{array}$ \\
\hline \multirow{2}{*}{$\begin{array}{l}\text { Porção } \\
\text { Central }\end{array}$} & \multirow{2}{*}{$\begin{array}{l}\text { Região da Lavrinha } \\
\text { (Copacel } 1, \\
\text { Clementino, Milton } \\
\text { Brasileiro, } \\
\text { Copacel } 2 \text { e Ernesto } \\
\text { Inferior }\end{array}$} & $\begin{array}{l}\text { Trifásicas aquo- } \\
\text { carbônicas }\end{array}$ & $\mathrm{H}_{2} \mathrm{O}+\mathrm{CO}_{2}+\mathrm{NaCl}$ & $\begin{array}{l}-60,1 \mathrm{a} \\
-56,8\end{array}$ & $\begin{array}{c}22,2 \mathrm{a} \\
30\end{array}$ & $\begin{array}{c}2,5 \mathrm{a} \\
8,8\end{array}$ & $\ldots$ & 0,3 a 9,6 & $\begin{array}{c}181 \mathrm{a} \\
331\end{array}$ \\
\hline & & Bifásicas Aquosas & $\begin{array}{c}\text { Il } \\
\mathrm{H}_{2} \mathrm{O}-\mathrm{NaCl}\end{array}$ & $\cdots$ & $\cdots$ & $\cdots$ & $\begin{array}{c}-8,5 \mathrm{a}- \\
0,2\end{array}$ & 0,3 a 11,8 & $123-205$ \\
\hline \multirow[b]{2}{*}{$\begin{array}{l}\text { Porção } \\
\text { Sul }\end{array}$} & \multirow[t]{2}{*}{ Pau-a-Pique } & $\begin{array}{l}\text { Trifásicas aquo- } \\
\text { carbônicas }\end{array}$ & $\begin{array}{c}\mathrm{I} \\
\mathrm{H}_{2} \mathrm{O}+\mathrm{CO}_{2}+\mathrm{NaCl} \\
\end{array}$ & $\begin{array}{l}-57,8 \mathrm{a} \\
-56,6 \\
\end{array}$ & $\begin{array}{c}14,8 \mathrm{a} \\
30,9 \\
\end{array}$ & 6 a 8,8 & $-\cdots$ & 4 a 7 & $\begin{array}{c}153,1 \mathrm{a} \\
342,8 \\
\end{array}$ \\
\hline & & Bifásicas Aquosas & $\begin{array}{c}\mathrm{Il} \\
\mathrm{H}_{2} \mathrm{O}-\mathrm{NaCl}\end{array}$ & $\cdots$ & $\cdots$ & $\cdots$ & $-18 a-1$ & 0,2 a 22,5 & $\begin{array}{c}98,4 \mathrm{a} \\
396\end{array}$ \\
\hline
\end{tabular}

$\mathrm{NaCl}$ eq., predominando valores entre 0,5 e $2,5 \%$ em peso de $\mathrm{NaCl}$ eq. Nas inclusões bifásicas aquosas (tipo II), a fusão do gelo ocorre entre $-6,4$ e $-0,4^{\circ} \mathrm{C}$ com pico entre $-2,4$ e $-0,4^{\circ} \mathrm{C}$. A temperatura de homogenização total se deu entre 150 e $270^{\circ} \mathrm{C}$, com pico entre 170 e $190^{\circ} \mathrm{C}$, enquanto a salinidade apresentou valores entre 0,5 e $5,5 \%$ peso $\mathrm{NaCl}$ eq., com pico entre 0,5 e $1,5 \%$ em peso de $\mathrm{NaCl}$ eq.

Nas amostras dos veios de quartzo da região da Lavrinha (depósitos Copacel 1, Clementino, Milton Brasileiro, Copacel 2 e Ernesto Inferior (Fig. 9B), as inclusões aquo-carbônicas (Tipo I) mostram temperatura de fusão do $\mathrm{CO}_{2}$ entre -61 e $-56,6^{\circ} \mathrm{C}$, com pico entre -58 e $-57,5^{\circ} \mathrm{C}$. A fusão do clatrato ocorre entre 2,5 a $8,8^{\circ} \mathrm{C}$ com predomínio entre 7,4 e $8,8^{\circ} \mathrm{C}$. Já a temperatura de homogeneização total, sempre para a fase líquida, varia de 180 a $340^{\circ} \mathrm{C}$, com dois picos, um entre 220 e $260^{\circ} \mathrm{C}$, e outro entre 280 e $300^{\circ} \mathrm{C}$. A salinidade nestas inclusões aquo-carbônicas concentra-se entre 0 a $10 \%$, predominando valores entre 3 e 5 em peso de $\mathrm{NaCl}$ eq. Já nas inclusões bifásicas aquosas (Tipo II), a fusão do gelo entre -9 e $-0,2^{\circ} \mathrm{C}$, com pico de -6 a $-4^{\circ} \mathrm{C}$. A temperatura de homogenização total se deu entre 120 e $225^{\circ} \mathrm{C}$ com dois picos, sendo um entre 135 e $165^{\circ} \mathrm{C}$ e outro entre $180 \mathrm{e}$ $195^{\circ} \mathrm{C}$, implica em salinidade entre 0,2 a $12 \%$ em peso de $\mathrm{NaCl}$ eq., com pico entre 6 e $9 \%$ em peso de $\mathrm{NaCl}$ eq.

Nas amostras dos veios de quartzo do depósito Pau-a-Pique (Fig. 9C), valores de $\mathrm{TfCO}_{2}$ medidos nas inclusões aquo-carbônicas (Tipo I) encontram-se entre $-57,8$ e $-56,6^{\circ} \mathrm{C}$, com pico de $-57,4$ a $-56,8^{\circ} \mathrm{C}$. A fusão do clatrato entre 6 e $8,8^{\circ} \mathrm{C}$ com predomínio entre 7,2 e 7,6. A temperatura de homogeneização total situa-se entre 150 e $360^{\circ} \mathrm{C}$, com pico entre 180 e $240^{\circ} \mathrm{C}$, indica que a salinidade nestas inclusões concentra-se entre 0 e $9 \%$ em peso de $\mathrm{NaCl}$ eq., predominando valores entre 5 e $6 \%$ em peso de $\mathrm{NaCl}$ eq. A fusão do gelo nas inclusões bifásicas (tipo II) ficou entre -18 e $-1{ }^{\circ} \mathrm{C}$ com pico entre -6 e $-2^{\circ} \mathrm{C}$. A temperatura de homogenização total se deu entre $80 \mathrm{a} 360^{\circ} \mathrm{C}$, com pico entre 150 e $210^{\circ} \mathrm{C}$. A salinidade apresentou valores entre 0,8 e $21,9 \%$ em peso de $\mathrm{NaCl}$ eq., com pico entre 5 e 10.

DISCUSSÃO E CONCLUSÕES Os dados obtidos no estudo das inclusões fluidas permitem concluir que os fluidos responsáveis pela mineralização ao longo da Faixa Móvel Aguapeí são aquosos e aquo-carbônicos, de baixa salinidade (Fig. 9). A temperatura da fusão do $\mathrm{CO}_{2}$ nas inclusões aquo-carbônicas nos depósitos entre $-61,2$ e $-56,6^{\circ} \mathrm{C}$, sugere a presença de outros voláteis associados à fase carbônica. Dos possíveis voláteis, a presença de $\mathrm{N}_{2}$ foi confirmada por Costa Neto (1998) em análise de 24 inclusões fluidas nos veios de quartzo do depósito Jair/Lavrinha por micro-espectrometria Raman.

A temperatura de homogeneização total do fluido hidrotermal representado tanto pelas inclusões do tipo aquosas como do tipo aquo-carbônicas ocorre entre 123 a $410^{\circ} \mathrm{C}$. Este intervalo de temperatura bastante amplo é corroborado por estimativa geotermométrica da formação da clorita hidrotermal obtida no depósito Pau-a-Pique $\left(240\right.$ a $\left.360^{\circ} \mathrm{C}\right)$ e nos depósitos da Região da Lavrinha (303 a $335^{\circ} \mathrm{C}$ ) (Barboza et al. 2001, Costa Neto, 1998).

A temperatura de homogeneização total das inclusões fluidas está no intervalo de temperatura dos depósitos do tipo lodegold $\left(175 \mathrm{a} 400^{\circ} \mathrm{C}\right)$, onde o ouro, sob o estado de oxidação $\mathrm{Au}^{+}$, é complexado e transportado por tiocomplexos sulfetados, tais como $\mathrm{Au}(\mathrm{HS})_{2}^{-}$.

A interação rocha/fluido nos depósitos do Grupo Aguapeí começou com a percolação de fluidos aquo-carbônicos (Fernandes 1999, Fernandes et al. 1999, Barboza et al. 2001). Estes fluidos precoces circularam durante o metamorfismo de fácies xisto verde sob temperaturas de 153 a $410^{\circ} \mathrm{C}$ (Fig. 9). Posteriormente, ocorreu a percolação de fluidos aquosos, como sugerem as inclusões aquosas tardias com temperatura de homogeneização de 98 a $240^{\circ} \mathrm{C}$.

Comparando os dados microtermométricos obtidos no depósito São Vicente, Pau-a-Pique e naqueles da região da Lavrinha, o primeiro apresenta salinidade mais baixa $(0,5$ a $5,8 \%$ em peso $\mathrm{NaCl}$ eq.) e temperatura de homogeniezação mais elevada (260$410^{\circ} \mathrm{C}$ ) para as inclusões aquo-carbônicas (Fig. 9 e tab. 1). Nas inclusões aquosas, a salinidade também é menor na mina de São Vicente. Já a temperatura de homogeneização nos três depósitos não difere muito para as inclusões aquosas (Fig. 9 e Tab. 1).

Dentre os depósitos da Faixa Móvel Aguapeí estudados, o da mina de São Vicente é que mais se assemelha com o depósito clássico de ouro em conglomerado Witwatersrand (África do Sul), onde os fluidos mineralizantes são aquosos e apresentam temperatura de homogeneização em torno de 140 a $208^{\circ} \mathrm{C}$, sendo a salinidade de 0,5 a $2,8 \%$ em peso de $\mathrm{NaCl}$ eq. em inclusôes com temperaturas de até $147^{\circ} \mathrm{C}$ e $6,6 \%$ em peso de $\mathrm{NaCl}$ eq. naquelas de mais alta temperatura (Frimmel \& Gartz, 1997) (Figs. 9 e 10).

Evidências mineralógicas e texturais indicam também a interação dos veios de quartzo com soluções meteóricas (Fernandes et al. 1999). Esta interação pode ter promovido importantes flutuações de Eh-pH, possibilitando a redistribuição do Au. 


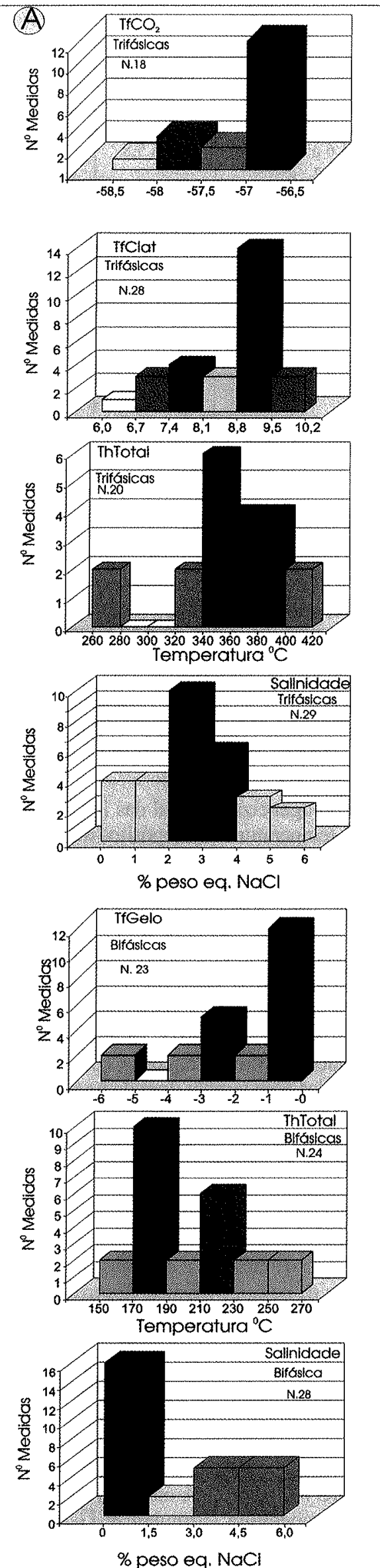

(B)
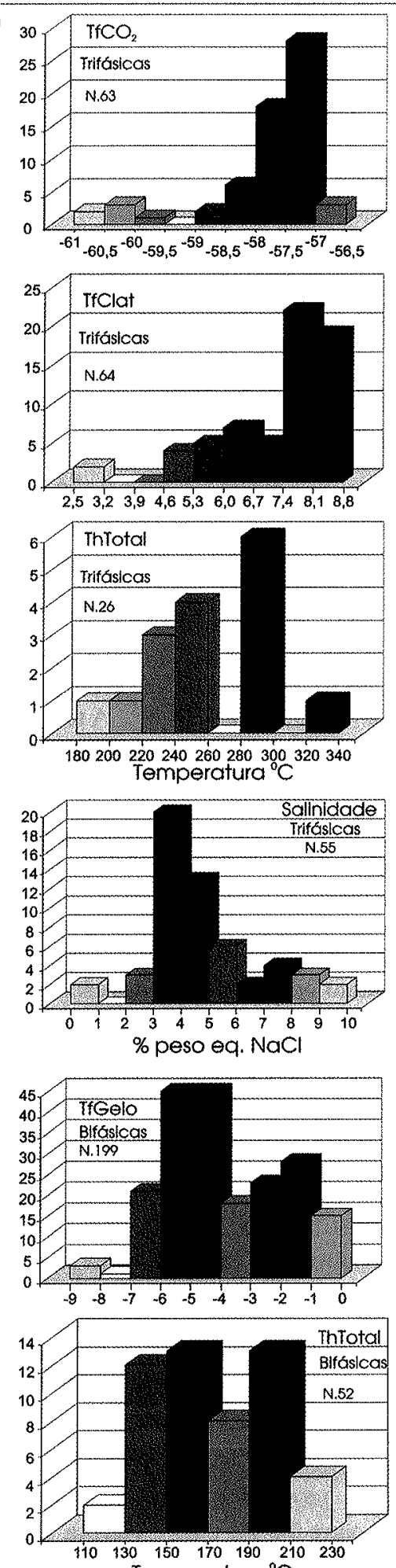

Temperatura ${ }^{\circ} \mathrm{C}$

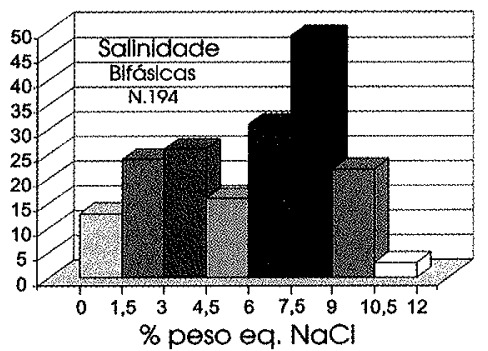

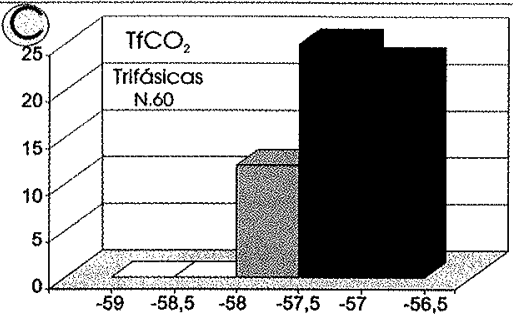
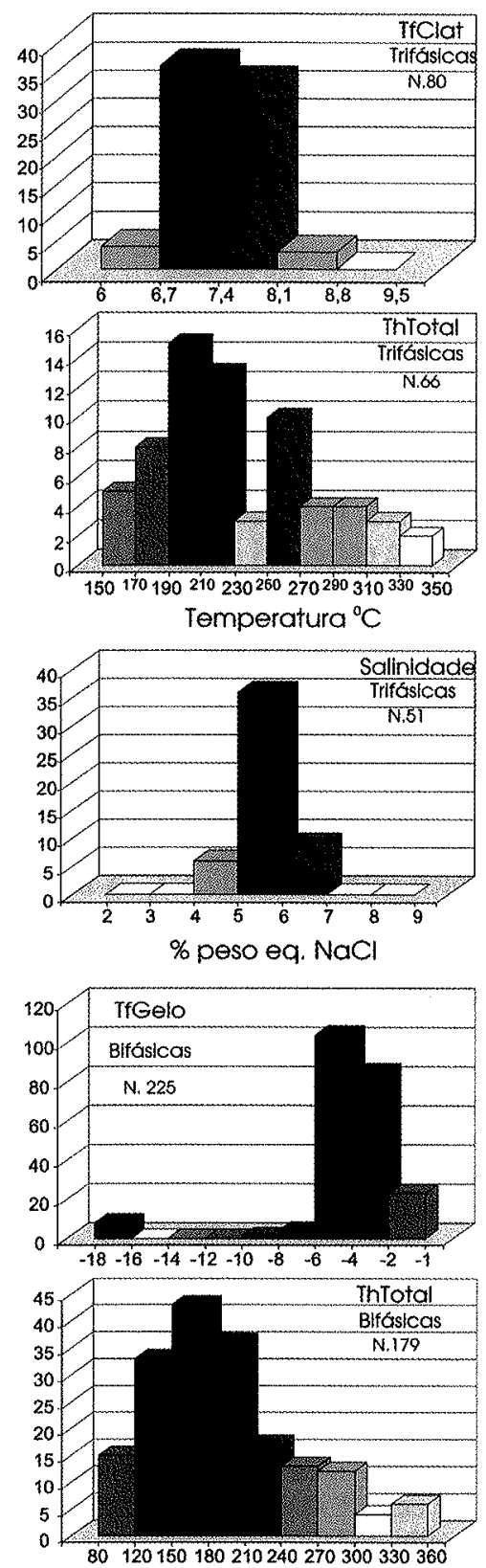

Temperatura ${ }^{\circ} \mathrm{C}$

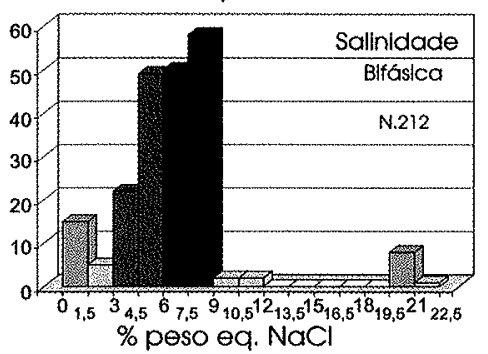

Figura 9 - Histogramas para os dados microtermométricos dos depósitos ao longo da Faixa Móvel Aguapei - (A) mina de São Vicente; (B) Depósitos da região da Lavrinha; (C) Depósito Pau-a-Pique. 

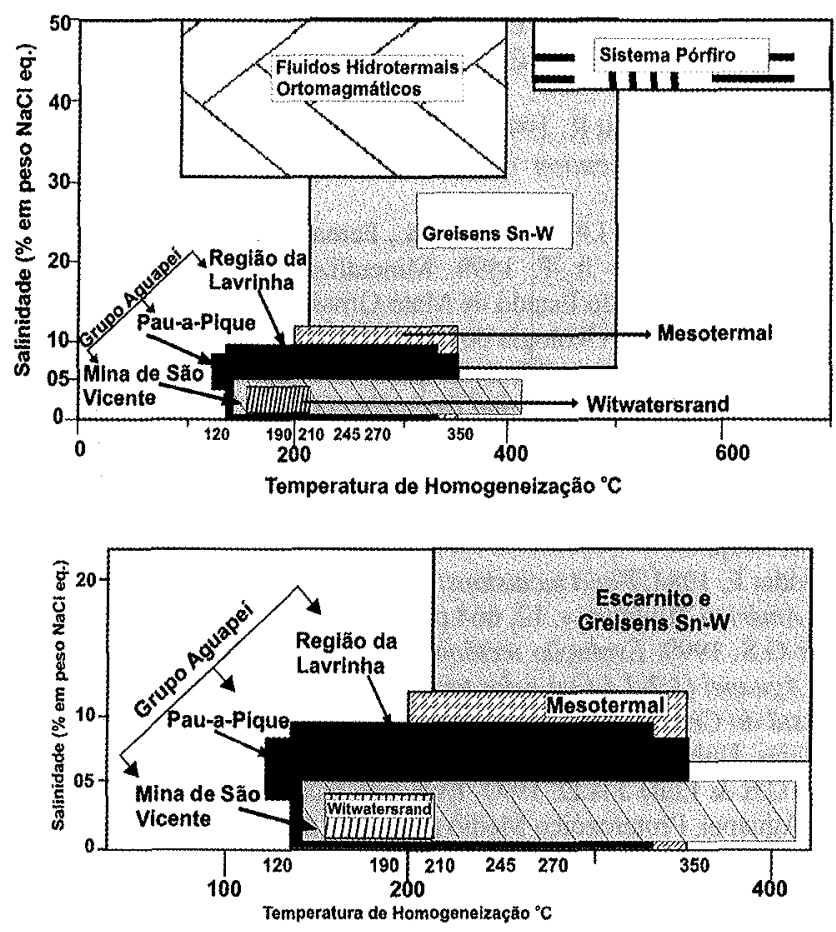

Figura 10 - Variação da temperatura de homogeneização e salinidade dos fluidos nos diferentes modelos metalogenéticos (Modificado de Lattanzi 1994), incluindo os dados de Groves \& Foster (1991), Large et al. (1988), Frimmel \& Gartz (1997) e Barboza (2001).

Como observado no depósito Pau-a-Pique, dentre as evidências minerais destaca-se a transformação de pirita em hematita, bem como aparecimento de martita e caulinita nos veios.

Das diversas hipóteses sobre a origem dos fluidos minera- lizantes em depósitos de ouro do tipo orogênico (fluidos mineralizantes oxidantes associados a granulitização, associados com lamprófiros, fluidos magmáticos, águas meteóricas e fluidos metamórficos segundo Muller \& Groves 1993, Burrows \& Sponner 1987, Nesbitt et al 1986, Kerrich \& Fryer 1979), aquelas relacionadas a fluidos metamórficos gerados durante devolatilização são consideradas essenciais na mineralização de depósitos auríferos incluindo aqueles associados a conglomerados (Supergrupo Witwatersrand, Grupo Jacobina, Grupo Aguapeí). $\mathrm{O}$ envolvimento de várias proporções de fluidos meteóricos e magmáticos é também aceito (modelo contínuo crustal - Colvine 1989, Groves et al. 1995), mas o papel de fluidos metamórficos é considerado de suma importância para a formação das províncias ricas em ouro (Phillips \& Powell 1992).

Baseado nos dados obtidos neste estudo e corroborado pelos dados de mapeamento regional (Fig. 3), a principal fonte dos fluidos hidrotermais responsáveis pela mineralização aurífera nos depósitos do Grupo Aguapeí está relacionada à devolatilização das rochas básicas e das formações ferríferas bandadas das seqüências vulcanossedimentares Rio Alegre e Pontes e Lacerda (Fernandes et al. 2003c).

Os dados petrográficos e geoquímicos, somados às idades ${ }^{40} \mathrm{Ar} /{ }^{39} \mathrm{Ar}$ em sericitas obtidas junto aos veios hidrotermais nos depósitos Ellus, Pau-a-Pique, Mineiros, Ernesto, Pombinha, Maraboa e Incra (Fernandes et al. 2003d), distribuídos de sul para norte na Faixa Móvel Aguapeí (Fig. 3), com idades entre $908,1 \pm 0,9 \mathrm{Ma}$ e $946,1 \pm 0,8 \mathrm{Ma}$ para a mineralização, evidenciam a circulação de fluidos no final da deformação imposta pela Orogenia Sunsas-Aguapeí, o que dá um caráter epigenético à formação dos depósitos.

Agradecimentos $\mathrm{O}$ primeiro autor gostaria de agradecer ao CNPq pela concessão de bolsa de doutorado. Ao Professor Bernhaard Buehn pelas valiosas discussões sobre os dados de inclusões fluidas. Aos revisores da Revista Brasileira de Geociências pelas sugestões ao manuscrito.

\section{Referências}

Almeida F.F.M., Hasui Y., Neves B.B. 1976. The upper precambrian of South América. São Paulo. Universidade de São Paulo. Boletim do Instituto de Geociências, São Paulo, 7:45-80.

Almeida F. F. M., Hasui Y., Neves B.B., Fuck R.A. 1977. Províncias Estruturais Brasileiras. In: SBG, Simpósio de Geologia do Nordeste, 8, Campina Grande, Anais, 363-391.

Alvarenga C.J.S \& Saes G.S. 1992. Estratigrafia e Sedimentologia do Proterozóico Médio e Superior da Regiâo Sudeste do Cráton Amazônico. Rev. Bras. Geociências, 22:493-499.

Barboza E.S. 2001. Geoquímica e microtermometria dos fluidos mineralizantes do Depósito Pau-a-Pique, sudoeste do Estado de Mato Grosso. Dissertação de Mestrado, Instituto de Geociências, Universidade Federal do Rio Grande do Sul, Porto Alegre, $149 \mathrm{p}$.

Barboza E.S., Pulz G.M., Ronchi L.H., Jelinek A.R., Pinho F.E., Quadros A.P. 2001. Estágios de mineralização no Depósito Aurífero Pau-aPique, Grupo Aguapeí, sudoeste do Estado de Mato Grosso, Brasil Central - Evidências de Química Mineral e Inclusões Fluidas. Rev. Pesquisas, 28(1):65-80.

Brown P. E. \& Hagemann S. G. 1994. MacFlinCor: a computer program for fluid inclusion data reduction and manipulation. In: B.de Vivo \& M.L. Frezzotti (eds). Fluid inclusions in minerals: methods and aplications. Virginia Tech, Blacksburg. p. 231-250.

Burrows D.R. \& Spooner E.T.C. 1987. Generation of a magmatic H2O$\mathrm{CO} 2$ fluid enriched in $\mathrm{Mo}, \mathrm{Au}$, and $\mathrm{W}$ within an Archean sodic granodiorite stock, Mink Lake, Northwestern Ontario. Economic Geo$\log$, 82:1931-1957.

Colvine A.C. 1989. An enpirical model for the formation of Archean gold deposits: products of final cratonização the Superior Province, Canada. Economic Geology Monograph, 6:37-53.

Costa Neto M.C. 1998. Estudo da interação fuido-rocha nos depósitos da Lavrinha, Distrito Aurifero de Pontes e Lacerda-MT. Dissertação de Mestrado, Instituto de Geociências, Universidade de Campinas, Campinas, $115 \mathrm{p}$.

Dardenne M.A. \& Schobbenhaus C. 2001. Metalogênese do Brasil. Editora Universidade de Brasília, Brasília, 392 p.

Dowling K. \& Morrison G. 1989. Application of quartz textures to the classification of gold deposits using North Queensland examples. Economic Geology Monograph, 6:342-355.

DNPM Ministério de Minas e Energia. 1996. Produção garimpeira de ouro por município e por empresas de mineração no estado de Mato Grosso. Divisão de Planejamento e Economia Mineral.

Fernandes C.J. 1999. Geologia do Depósito Pau-a-Pique e guias prospectivos para ouro no Grupo Aguapei, sudoeste do Estado de Mato Grosso. Dissertação de Mestrado, Instituto de Geociências, Universidade Federal do Rio Grande do Sul, Porto Alegre, $134 \mathrm{p}$.

Fernandes C.J., Pulz G.M., Oliveira S.A., Lima e Cunha M.C., Barboza E.S., Pinho F.E.C., Quadros, A.P. 1999. Diferenças químicas e texturais entre os veios de quartzo férteis e estéreis no Depósito Aurífero Pau-a-Pique (Grupo Aguapeí, Estado de Mato Grosso). Pesquisas, 26:91-101.

Fernandes C.J., Ruiz A.S., Pinho F.E.C., Kuyumjian R.M. 2003a. Compartimentação da deformação na Faixa Móvel Aguapeí, sudoeste do Cráton Amazônico - Brasil, e as mineralizações auríferas associadas. Rev. Bras. de Geociências - no prelo. 
Fernandes C.J., Ruiz A.S., Kuyumjian R.M., Pinho F.E.C. 2003b. Geologia e controle estrutural dos depósitos Auríferos do Grupo Aguape - Região da Lavrinha, Sudoeste do Cráton Amazônico - Brasil. Rev. Bras. de Geociencias - no prelo.

Fernandes C.J., Kuyumjian R.M., Pulz G.M., Pinho F.E.C. 2003c. Os depósitos auríferos do Grupo Aguapeí, Estado de Mato Grosso-Brasil, e as características que os diferenciam dos modelos clássicos de ouro em conglomerados. Rev. Pesquisas - no prelo.

Fernandes C.J, Geraldes M.C., Tassinari C.C.G., Kuyumjian R.M. 2003d. Idades 40ar/39ar para os depósitos auríferos da Faixa Móvel Aguapeí, porção sudoeste do Cráton Amazônico, estado de Mato Grosso. In: Simpósio de Geologia do Centro-Oeste, 8, Cuiabá, Anais, 93-96.

Figueiredo A.J., Barros A.M., Eulália Filho A., Rodrigues A.P., Barreto B.F., Couto J.G.P., Reichl, J.L, Costa S.A.G., Resende Filho S.T., Pastore Júnior W.P., Berbert C.O.; Araújo A.G., Trigues J.A.; Melo J.C.R. 1974. Projeto Alto Guaporé. Goiânia. DNPM/CPRM. Relatório Vol. 2

Frimmel H.E. \& Gartz V.H. 1997. Witwatersrand gold particle chemistry matches model of metamorphosed, hydrothermal altered placer deposits. Mineralium Deposita, 32:523-530.

Geraldes M.C., Figueiredo B.R., Tassinari C.C.G., Ebert H.D. 1997. Middle Proterozoic vein-hosted gold deposits in the Pontes e Lacerda region, southwestern Amazonian Craton, Brasil - International Geology Review, 39:438-448.

Geraldes M.C., Van Schmus W.R., Condie K.C., Bell S., Teixeira W., Babinski M. 2001. Proterozoic geologic evolution of the SW part of the Amazonian Craton in Mato Grosso state, Brazil. Precambrian Research. 111: 91-128.

Gilligan L. B. \& Marshall B. 1987. Textural evidence for remobilization in metamorphic enviroments. Ore Geology Reviews. 2:205-229.

Groves D.I. \& Foster R.P. 1991. Archaean lode gold deposits. In: R.P Foster (ed.) Gold Metallgeny and Exploration, Londres, p. 63-103.

Groves D.I., Ridley J.R., Bloem N.J., Gebre-Mariam M., Hagemann S.G., Hronsky J.M.A., Knight J.T., Mcnaughton N.J., Ojala J., Vielreicher R.M., Mccuaig T.C., Holyland. 1995. Lode-gold deposits of the Yilgarn block: products of Late Archean crustal-scale overpressured hydrothermal. In: M.P. Coward, \& A.C. Ries (eds) Early Precambrian Processes. Geological Society Special Publication, v. 95, p.155-172.

Hodgson C.J. 1989. The structure of the shear related vein-type gold deposits: a review. Ore Geology Reviews, 4:231-373.

Large R., Huston D., McGoldrick, P., McArthur G., Ruxton P. 1988. Gold distribution and genesis in Paleozoic Volcanogenic massive sulphide system, Eastern Australia. In: A.D.T Goode \& L.I. Bosma (eds) Geological Society of Australia Abstracts Series, Extended Abstracts Oral Programme, n. 22, p. 121-126.

Lattanzi P. 1994. Fluids in ore deposits, evidence from and applications of fluid inclusions. In: B. De Vivo \& M.L. Frezzotti (eds). Fluid Inclusions in Minerals: Methods and aplication. Short Course of the Group (IMA) "Inclusions in Minerals", p. 297-301.

Litherland M. \& Bloomfield K. 1981. The Proterozoic History of Eastern Bolivia. Precambrian Research, Amsterdam, 2:157-179.

Litherland M., Klinck B.A., O'Connor E.A., Pitfield P.E.J. 1985. Andeantrending mobile belts in the Brazilian Shield. Nature, 314:345-348.

Litherland M. \& Power G. 1989. The geology and geomorphology evolution of Serrania Huanchaca, easten Bolivia: the legendary "lost World". Journal South American Earth Science, 2:1-17.

Kerrich R. \& Fryer B.J. 1979. Archean precious-metal hydrothermal systems, Dome Mine, Abitibi Greenstone Belt. II. REE and oxygen isotope relations. Canadian Journal of Earth Science, 16:440-458.

Monteiro H., Macedo P.M., Silva M.D., Moraes A.A., Marcheto C. M. I. 1986. O Greenstone Belt do Alto Jauru. In: SBG, Congr. Bras. Geol., 35, Goiânia, Anais, v. 2, p. 630-647.

Muller D., Groves D.I. 1993. Direct and indirect associations between potassic igneous rocks, shoshonites and gold-copper deposits. Ore Geology Reviews, 8:383-406.

Nesbitt B.E., Murowchick J.B., Muehlenbachs K. 1986. Dual origen of lode gold deposits in the Canadian Cordillera. Geology, 14:506-509.

Passos Jr. G.G., Silva J.A., Martins S.C., Ramari M.O., Leite J.A.D., Pinho F.E.C. 1997. Geologia estrutural da cava sul da mina de São
Vicente e suas relações com as mineralizações auríferras - Vila Bela - MT. In: Simpósio de Geologia do Centro-Oeste, 6, SBG, Cuiabá, Anais, 71-72.

Phillips G.N., Powell R. 1992. Gold-only provinces and their commom features. Contribution of the Economic Geology Research Unit, v. $43,27 \mathrm{p}$.

Pinho F.E.C., Leite J.A.D., Saes G.S., Fernandes C.J., Ruiz A.S., Pulz G.M., Chemale Jr. F. 1999. Mineralizações auríferas no Grupo Aguapeí, oeste do Estado de Mato Grosso, fronteira Brasil-Bolívia. In: Simpósio de Geologia do Centro Oeste, 7 \& Simpósio de Geologia de Minas Gerais, 10, Anais, p. 28-28.

Ramsay J.G. 1967. Folding and fracturing of rocks. McGraw-Hill, New York, p. 568

Ramsay J.G. \& Huber M. I. 1983. The Techniques of Modern Structu ral Geology: fold and Fractures. Academic Press Inc., London, v. 1,391p.

Roedder E. 1984. Fluid inclusions: Mineralogical Society in Mineralogy América, Riviews, v. 12,664 p.

Saes G.S. 1999. Evolução tectônica e paleogeográfica do Aulacógeno Aguapei $(1,2-1,1 \mathrm{Ga})$ e dos terrenos do seu embasamento na porção sul do Cráton Amazônico. Tese de Doutoramento, Inst. de Geociências, Universidade de São Paulo, São Paulo, 135p.

Saes G.S \& Leite J.A.D. 1993. Evolução tectono-sedimentar do Grupo Aguapeí, Proterozóico Médio na porção meridional do Cráton Amazônico: Mato Grosso e Oriente Boliviano. Rev. Bras. Geociências, 23:31-37.

Saes G.S., Leite J.A.D., Weska R.K. 1984. Geologia da Folha Jauru (SD - 21 - Y - C - III): Uma síntese dos conhecimentos. In: SBG, Cong. Bras. Geol., 33, Rio de Janeiro, Anais, v.5, p. 2193-2204.

Saes G.S., Pinho F.E.C., Leite J.A.D. 1991 . Coberturas sedimentares do Proterozóico Médio no Sul do Cráton Amazônico e suas mineralizações auríferas. In: SBG/ Núcleo Centro Oeste, Simpósio de Geologia do Centro Oeste, 3, Anais, p.45-52.

Santos A.A., Silva A.L., Santos T.J.S., Ruiz A.S., Fernandes C.J., Pinho F.E.C. 2001. Análise estrutural dos depósitos auríferos Copacel e Ernensto - região de Pontes e Lacerda (MT). In: Simpósio Nacional de Estudos Tectônicos - SNET, 8, e International Symposium on Tectonics of the Brazilian Geological Society, 2, Pernambuco, Anais, v.1 p. 169-172.

Scabora J.A. 1992. Mineração Santa Elina, Vila Bela. Relatório Interno, $23 \mathrm{p}$.

Scabora J.A. \& Duarte C.L. 1998. A jazida de ouro de São Vicente - município de Nova Lacerda - MT. A Terra em Revista, 4:32-42.

Seward T.M. 1973. Thio complexes of gold in hydrothermal ore solutions. Geochemistry Cosmochemical Acta, 37:379-399.

Shepherd T., Rankin A.H., Alderton D.H.M. 1985. A Practical Guide to Fluid Inclusion Studies. 1 ed., Blackie \& Son Ltd, New York, 229p.

Silva J.J.F. \& Chemale Jr. F. 1997. Geologia estrutural e química mineral da Mina de São Vicente, oeste do estado de Mato Grosso. In: SBG, Simpósio de Geologia do Centro-Oeste, 6, Cuiabá, Anais, 53-58.

Silva J.J.F., Chemale Jr. F., Pulz G.M. 1997. Caracterização do minério aurifero da Mina de São Vicente, oeste do estado de Mato Grosso Brasil. In: Caracterização de minérios e rejeitos de depósitos minerais brasileiros, Brasília, DNPM/DIREX/ PADCT/GTM, Anais, 38-42.

Souza E.P. \& Hildred P.R. 1980. Contribuição ao Estudo da Geologia do Grupo Aguapeí, Oeste de Mato Grosso. In: SBG, Congr. Bras. Geol., 31, Balneário de Camboriú, Anais 2: 813-825.

Tassinari C.C.G. \& Macambira M.J.B. 1999. Geochronological Provinces of the Amazonian Craton. Episodes. 22(3):174-182.

Tassinari C.C.G., Bettencourt J.S., Geraldes M.C., Macambira M.J.B., Lafon, J.M. 2000. The Amazonian Craton. In: U.G. Cordani, E.J. Milani, A.Thomaz Filho, D.A. Campos (eds.) Tectonic Evolution of South America. Internationa Geological Congress, 31s, Rio de Janeiro, p. 41-95.

Trompette R. 1994. Geology of western Gondwana (2000-500Ma). Balkema, $350 \mathrm{p}$.

Vernon R.H. 1986. Evaluation of the "quartz-eye" hypothesis. Economic Geology, 81:1520-1527

Manuscrito A-1552

Revisão aceita em 29 de setembro de 2006 